\title{
Effect of Graded Oil Palm Kernel Shells on Compaction of Weak o Problematic Sub-Grade Soils*
}

\author{
${ }^{1} \mathrm{M}$. Affam, ${ }^{1}$ R. Ewusi Wilson and ${ }^{2} \mathrm{D}$. Asenso-Gjambibi \\ ${ }^{1}$ University of Mines and Technology, Tarkwa \\ ${ }^{2}$ CSIR- Building and Road Research Institute, Kumasi
}

Affam, M., Ewusi Wilson, R. and Asenso-Gjambibi, D. (2019), "Effect of Graded Oil Palm Kernel Shells on Compaction of Weak Sub-Grade and Problematic Soils", Ghana Mining Journal, Vol. 19, No. 2, pp. 17-25.

\begin{abstract}
Sub-grade is the ultimate load bearer of vehicular traffic load in a pavement structure. A weak sub-grade or problematic soils require some improvements like soil stabilisation, soil reinforcement and/or capping of the sub-grade layer. These sub-grade improvement methods increase the total project cost because non-local materials such as cement, geosynthetics and hydrated lime are commonly used. The use of graded oil palm kernel shells (OPKS) which are local, cheaper and readily available as a soil improvement material was assessed in this research. This assessment was done by mixing sub-grade material with 2.8 $\mathrm{mm}, 5 \mathrm{~mm}$ and $10 \mathrm{~mm}$ graded OPKS. $10 \%, 20 \%$ and $30 \%$ of each graded OPKS was added separately to the soil to form nine composite materials. These composite materials including the natural soil were tested for their California Bearing Ratio (CBR) values. The investigation proved that the composite made of $20 \% 2.8 \mathrm{~mm}$ graded OPKS yielded a soaked CBR of 23.5 $\%$ which is a $197.47 \%$ increase in soaked CBR compared to that of the natural soil. The soaked CBR samples of the graded OPKS composite materials absorbed lesser amounts of water in comparison to that of the natural soil. This behaviour implies that some capillary force created at un-soaked condition in the composite materials was preserved; therefore, the composite materials generally have higher CBR values than the natural soil.
\end{abstract}

Keywords: Oil Palm Kernel Shells (OPKS), Problematic Soils, Lightweight Aggregate (LWA)

\section{Introduction}

Roads traverse over different terrains and that both competent and problematic sub-grade soils may be traversed. It has been noted to be difficult and sometimes impractical to re-route some road course because of the occurrence of poor sub-grade materials. Weak or problematic sub-grade materials eventually cause the deformation of the roads pavement structure as a result of their inability to support heavy vehicular loads (Zhu and Liu, 2008). Therefore, such unwarranted materials along the road corridor may require some improvements or reinforcements to enhance its usage.

However, due to increasing population and industrialization throughout the world, there are various forms of waste and by-products being generated on daily basis that could be tested for their soil improvements properties. Few of such waste materials tested with positive results include blast furnace slag, saw dust, rice husk ash, cement kiln dust, bottom ash and fly ash.

The engineering benefits obtained from using these industrial wastes to improve soils include reducing their thermal conductivity, decreasing weight of constructional materials, increasing tensile and compressive strength, restricting swelling tendencies and reducing soil brittleness (Singh et al., 2008).

Little or no such research has been conducted on Oil Palm Kernel Shell (OPKS) to assess its propensity or otherwise to sub-grade improvement. OPKS produced by both small scale producers and industries are sold as bio-fuel but majority are heaped as waste causing environmental problems.

Palm oil industries seldomly use small fraction of the OPKS to produce heat for boilers. The rest are dumped as waste which could be accessible for activated carbon manufacture at no or very low cost Currently nearly 14000 tons of OPKS are generated annually by some four oil palm plantations in Ghana (Lartey et al., 1999).

This research therefore focuses on using graded OPKS as a soil improvement material for weak subgrade. OPKS is observed as cheaper alternative if found to be mechanically competent due to its relative abundance. This agricultural by-product is abundant and wide spread through several local communities in Ghana and could be assessed for its engineering usefulness.

\subsection{Problematic Soils}

A soil is considered to be problematic in engineering sense when it undergoes excessive settlement, expands, swells, collapses, disperses, lacks strength or is soluble. These properties are unique to the soil because they happen due to their poor pore spaces and pressure, the soil fabric and or mineralogy (Briscolland and Chown, 2001).

These soils are characterised by their damaging attributes which include erosion, expansion, excessive creep, high compressibility, heaving, 
subsidence, dispersion and swelling of the soil (Bell and Culshaw, 2001). Problematic soils have some additional unique properties including low bearing capacity, high compressibility, high water absorption, low permeability, soft to fine grained, among others. (Indraratna et al., 2011).

According to Adejumo et al., 2012) one of the most disturbing type of problematic soils are:

(i) Expansive or shrinkable soils (Vertisols)

(ii) Tropical compressible residual red silty clay soils and sensitive halloysitic soils.

\subsection{Sub-grade Soil}

The natural layer or native soil upon which road is built is regarded as sub-grade. This naturally occurring material is regarded as an imported soil layer upon which an embankment is built for road foundation.

The sub-grade strength is therefore very important parameter that determines the thickness of the road pavement structure. Sub-grade strength is measured with the California Bearing Ratio (CBR) test which is also dependent on the soil composition (Mathew and Rao, 2007). In engineering domain, a soil layer or a sub-grade material is defined to have a weak, problematic and of poor quality if it has a CBR value less than $15 \%$ (Anon., 2015).

\subsection{Ground Improvements Techniques}

Depending on ease of access and technology, varieties of soil improvement techniques exist for adoption. This involves the alteration of any property of a soil designed to enhance its bearing pressure for the purpose of increasing its engineering performance. Soil improvement techniques can be achieved by increasing the shear strength, reducing compressibility as well as permeability (Raju and Valluri, 2008). This could be achieved by adopting the right remediation method to the weak soil. Usually, densification, consolidation, modification, load transfer, chemical or by material addition has been observed to be the most appropriate approach.

Thus, improvements in ground condition have become necessary in recent times due to accelerated development globally leading to limited land space and the need to maximise all available lands (Ameratunga, 2013).

\section{Resources and Methods}

\subsection{Materials}

The sequence of test methods applied and materials used including the natural soil and the composite
OPKS materials are presented in the flow chart in Fig. 1.

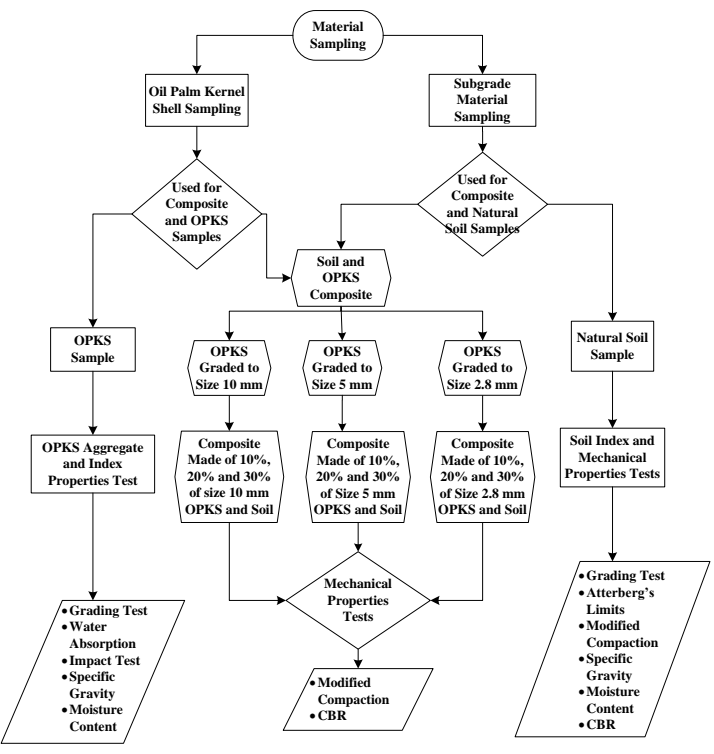

Fig.1 Flow Chart of Test Methods and Materials

\subsubsection{Soil Sample Preparation for Test}

The soil samples were air dried in the laboratory with the moisture content monitored for at least two days until there was constant moisture content or relatively small changes in moisture content. Upon drying, the soil samples were then prepared for soil tests.

The sub-grade material and OPKS samples were prepared and tested for their index properties. Varying proportions of graded OPKS were then added to the natural soil and the resulting composite materials were tested for their mechanical properties.

\subsubsection{Oil Palm Kernel Shells (OPKS)}

Oil Palm Kernel Shells (OPKS) are organic, carbonaceous, porous, absorbent, flaky and hard byproducts from oil palm fruit processing (Fig. 2) OPKS consists of small size particles between $0 \mathrm{~mm}$ to $5 \mathrm{~mm}$, medium size particles between $5 \mathrm{~mm}-10$ $\mathrm{mm}$ and large size particles between $10 \mathrm{~mm}-15 \mathrm{~mm}$ (Alengaram et al., 2010a).

It is produced by both small and large scale industries are sold as bio-fuel. Occasionally, they are heaped as waste causing environmental nuisance. The large Palm Oil industries mostly use approximately $5 \%$ of the OPKS produced. They are often burnt with palm fibre to produce heat for their boilers. The rest are dumped as waste which can be accessible for activated carbon manufacture at no or very low cost. .About 14000 tons of OPKS are 
generated annually by four major Oil Palm Plantations in Ghana (Lartey et al., 1999).

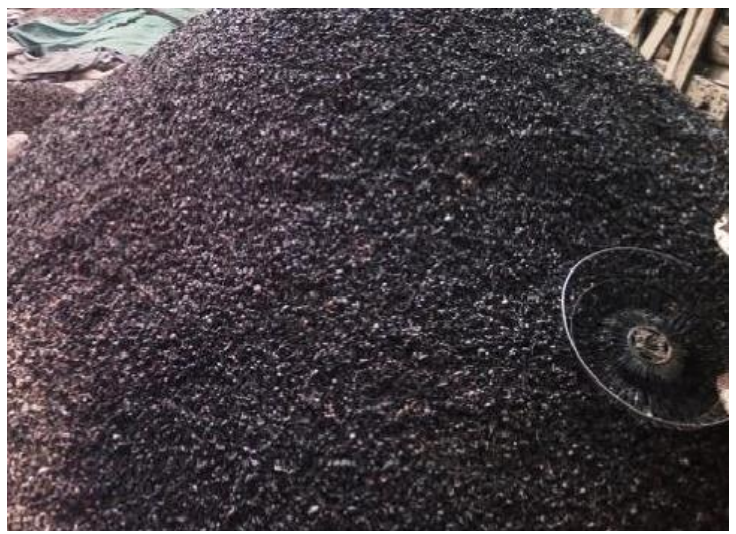

Fig. 2 Oil Palm Kernel Shells (OPKS)

OPKS is an agronomic solid waste or by-product. It is also classified as a light weight aggregate (LWA) that can be used to make lightweight aggregate concrete (LWAC). This application has been used in Malaysia for more than two decades. (Yap et al., 2013).

The large size of OPKS is found to be about $15 \mathrm{~mm}$. However the dimensions of OPKS can differ subject to the technology used to crack the palm nuts. Usually, length of the shells has been observed to range from $2 \mathrm{~mm}$ to $15 \mathrm{~mm}$. The breadth fluctuates between $1.5 \mathrm{~mm}$ to $3 \mathrm{~mm}$ The shape often comes as parabolic, angular, flaky, has smooth concave to convex surface. (Alengaram et al., 2008).

\subsection{Methods Used}

\subsubsection{Preparation of Graded OPKS}

OPKS material was graded into three different sizes namely large, medium and small aggregate. The OPKS material was subjected to natural water content test, specific gravity test and particle size analysis. It was further subjected to aggregate water absorption and aggregate impact value (AIV) tests.

The OPKS passing $15 \mathrm{~mm}$ test sieve and retained on $10 \mathrm{~mm}$ test sieve was classified large (or $10 \mathrm{~mm}$ ) graded. Portion of sample passing the $10 \mathrm{~mm}$ sieve and retained on $5 \mathrm{~mm}$ test sieve was regarded medium (or $5 \mathrm{~mm}$ ) graded OPKS. The undersize passing the $5 \mathrm{~mm}$ mesh size and retained on the 2.8 $\mathrm{mm}$ test sieves was also categorized as small (2.8 $\mathrm{mm}$ ) graded OPKS (Fig. 3). The samples were then washed clean with and air dried.

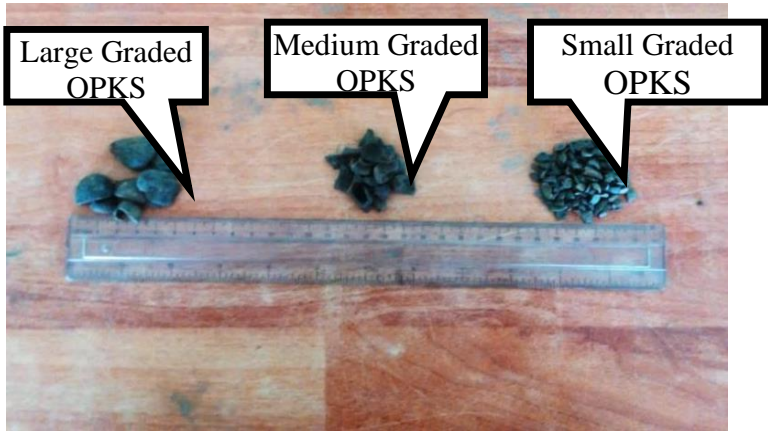

Fig. 3 Composition of Graded OPKS

The composite materials were made up of admixture of the natural soil and $10 \%, 20 \%$ or $30 \%$ weight of each $10 \mathrm{~mm}, 5 \mathrm{~mm}$ and $2.8 \mathrm{~mm}$ graded OPKS to the soil. A total of nine composite materials were made. Fig. 4 shows the mixed soil and graded OPKS for the preparation of the composite graded OPKS soil sample.

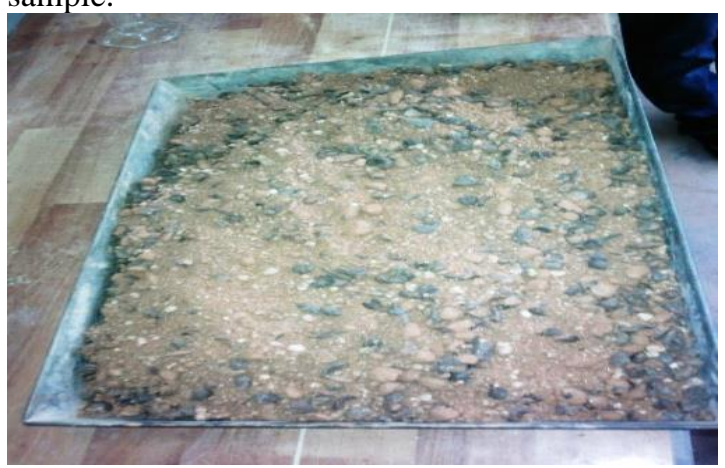

Fig. 4 Composite of a Graded OPKS and Natural Soil

\subsubsection{Aggregate Sieve Analysis}

The particle size analysis was conducted by dry sieving about $1200 \mathrm{~g}$ of composite sample through a nest of test sieves with apertures sizes from $20 \mathrm{~mm}$ to $75 \mu \mathrm{m}$ in accordance with BS 812: Part 103. The proportion of OPKS in each batch was between $10 \%$ to $30 \%$. The sieve analysis of the composite soil was carried out to separate the material into different fractions based on their particle sizes. It expressed quantitatively the proportions by mass, of various size of particles present and drawn graphically on a particle size distribution curve.

\subsubsection{OPKS Aggregate Relative Density and Water Absorption}

A minimum sample size of $1200 \mathrm{~g}$ of each of 2.8 $\mathrm{mm}, 5 \mathrm{~mm}$ and $10 \mathrm{~mm}$ graded OPKS were submerged in water ensuring that no air bubbles were trapped in the submerged OPKS for 24 hours. Afterwards, the graded OPKS samples were gently surfaced dried using a dry cloth. The surface dry graded OPKS samples were again transferred onto a second dry cloth and air dried until completely surface-dry, weighed to the nearest $0.5 \mathrm{~g}$ and oven 
dried at $105^{\circ} \mathrm{C}$ overnight to determine the moisture content.

From the masses of the oven dried OPKS samples and the surface-dry OPKS relative density and the water absorption of each graded OPKS was determined as per BS 812 specifications. The apparent relative density $\left(\rho_{d}\right)$ of an oven dried OPKS was calculated using Equation (1):

$$
\rho_{d}=\frac{D}{A-(B-C)}
$$

where, A is the mass of the saturated surface-dry OPKS

$\mathrm{B}$ is the mass of the container containing sample filled with water

$\mathrm{C}$ is the mass of container filled with only water

$\mathrm{D}$ is the mass of the oven-dry aggregate

This test was relevant to compaction analysis for the calculation of air voids ratio and it was also used to confirm the lightweight characteristics of OPKS.

\subsubsection{Aggregate Impact Value (AIV)}

The aggregate crushing value gives a relative measure of the resistance of the aggregate to crushing under gradually applied compressive force. The graded OPKS was assessed for its ability to resist sudden impact or shock load. The samples were soaked in water for 24 hours and afterward removed and surface dried. This was done to test the sample in its worse condition. The test sample was conducted as specified by the BS 812: Part 112. Result above $30 \%$ was regarded anomalous.

The material for the standard test consisted of aggregate passing the sieve size and retained on 2.36 $\mathrm{mm}$ sieve and thoroughly separated on these sieves before testing. The ratio of the mass of fines formed to the total sample mass in each test was expressed as percentage (Equ.2):

$$
\text { Pencentage fines }=\frac{A}{B} x 100
$$

where

A is the mass of surface dry samples $(\mathrm{g})$ $\mathrm{B}$ is fraction passing the sieve $(2.36 \mathrm{~mm})$ for separating the fines $(\mathrm{g})$

The test was repeated three times and the mean values taken as shown in Table 1 .

\begin{tabular}{|c|c|c|c|}
\hline \multicolumn{2}{|c|}{ Test Parameters } & $\begin{array}{l}\text { Natural } \\
\text { Soil }\end{array}$ & OPKS \\
\hline \multirow{3}{*}{$\begin{array}{l}\text { Grading } \\
\text { Analysis }\end{array}$} & $\begin{array}{l}\text { Proportions of } \\
\text { Gravel }(\%)\end{array}$ & 4.5 & 98.7 \\
\hline & $\begin{array}{l}\text { Proportions of } \\
\text { Sands }(\%)\end{array}$ & 42.1 & 1.2 \\
\hline & $\begin{array}{l}\text { Proportions of } \\
\text { Fines }(\%)\end{array}$ & 53.3 & 0 \\
\hline \multicolumn{2}{|c|}{$\begin{array}{l}\text { Unified Soil Classification } \\
\text { System (USCS) }\end{array}$} & $\mathrm{CL}$ & GP \\
\hline
\end{tabular}

Table 1 Grading Natural Soil and OPKS

\subsubsection{California Bearing Ratio (CBR) Test}

The CBR test was conducted in accordance with ASTM D1883. Three CBR samples were prepared from $21 \mathrm{~kg}$ of soil passing the $19 \mathrm{~mm}$ test sieve. These samples were mixed thoroughly with water to determine the Optimum Moisture Content (OMC). The moist soil mixture was bagged in an airtight container and stored for a minimum of 24 hours before compacting.

The compacted CBR samples were tested in a calibrated load frame for their un-soaked CBR values. Three extra CBR samples were compacted and soaked in water for 96 hours. After this, the soaked samples were removed from the water and allowed to drain for about 15 minutes. The drained samples were then tested for their soaked values. The CBR values were used to classify the bearing strength of the soil sample.

\section{Results and Discussion}

\subsection{Particle Size Analysis}

Grading curve of the natural soil in Fig. 5 shows that, the soil is composed mainly of fine grained particles. $53.3 \%$ of soil is fine grained, $42 \%$ is sand and 4.5 $\%$ is gravel. Using the grading curve and the liquid limit the soil classifies as clay (CL) The soil was further classified under the group name; sandy lean clay as per Unified Soil Classification System (USCS) since the fine grained soil passing $75 \mu \mathrm{m}$ exceeds $50 \%$ and the liquid limit is within $0 \%-50$ $\%$.

The grading analysis of the OPKS material indicated that it has abundant gravel size particles and very little fines. $98.7 \%$ of the OPKS material is gravel size and $1.2 \%$ is sand size. The grading analysis results of the natural soil and OPKS are presented in Table .1. From the grading curve of the OPKS (Fig. $5)$, the material is described as poorly graded gravel $(G P)$ using the Unified Soil Classification System (USCS). 


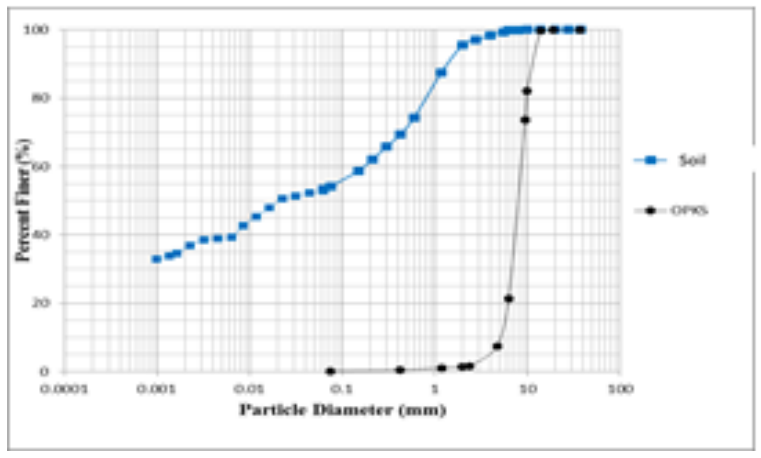

Fig.5 Grading Curves of Natural Soil and OPKS

The compaction characteristics of the natural soil and the composite materials are summarised in Table 1. BS heavy compaction test results show that the MDD of the natural soil is $1.81 \mathrm{~g} / \mathrm{cm}^{3}$ and the $\mathrm{OMC}$ is $15 \%$. At MDD, air voids ratio is $6.5 \%$. From Fig. 6a-b, the air voids ratios of all compacted composite materials with $10 \%$ and $20 \%$ graded OPKS are lesser than that of the compacted natural soil.

Nonetheless, the air voids ratios of all compacted composite materials with $30 \%$ graded OPKS are the highest compared to that of the natural soil and the other composite materials. This behaviour suggests that the compaction of composite material with 10 $\%$ and $20 \%$ graded OPKS achieved a higher densification compared to that of the compacted natural soil.

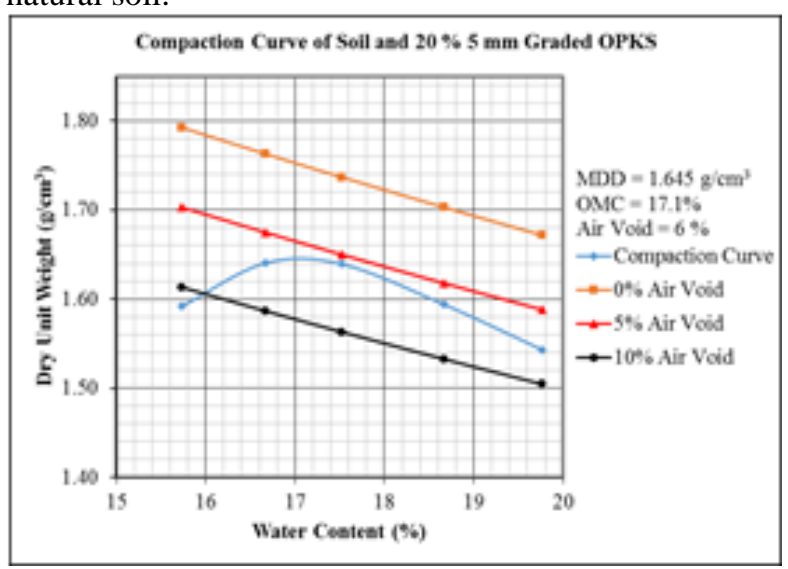

Fig. 6a Compaction Curves of Sub-Grade Material and Composite Materials

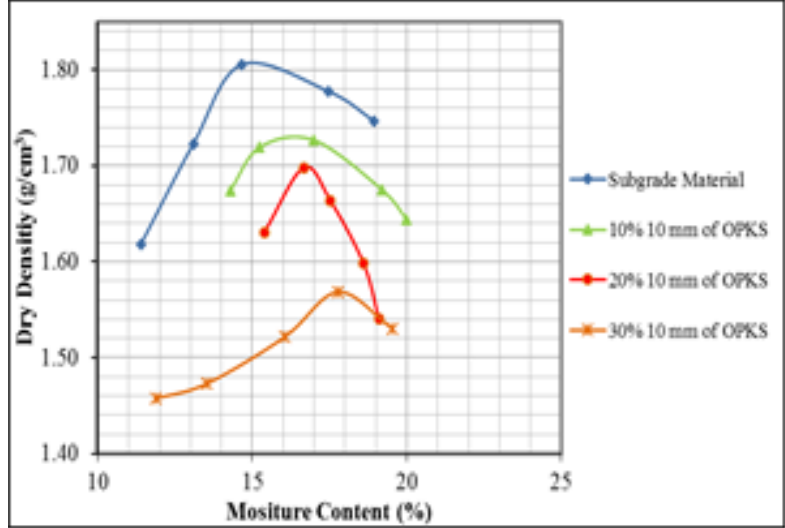

Fig.6b Modified Compaction Curves of Natural Soil and $10 \mathrm{~mm}$ OPKS

MDD results of the composite materials are lesser than that of the natural soil. However, all the OMC of the composite materials increased when compared with that of the natural soil. This behaviour confirms the MDD and OMC relationships observed by Madjadoumbaye et al., (2013) for composites of OPKS and laterite. The compacted properties of the natural soil and the composite materials saw considerable improvement (see Table 2).

\subsection{Aggregate Impact Value (AIV) and Water Absorption}

The wet and dry Aggregate Impact Value (AIV) of the graded OPKS are presented in Fig, 7a. The wet and dry AIV results of the $2.8 \mathrm{~mm}$ graded OPKS are $3.04 \%$ and $5.83 \%$ respectively while those for the 5 mm graded OPKS are $3.45 \%$ and The average water absorption of the $2.8 \mathrm{~mm}$ graded material6.39 $\%$. The results for $10 \mathrm{~mm}$ graded OPKS are $4.41 \%$ and $8.07 \%$ respectively. The dry state AIV results of the test suggest that upon wetting, the OPKS's resistance to crushing increased for all graded aggregates. Based on the AIV results of all three graded OPKS, the $2.8 \mathrm{~mm}$ graded OPKS is the most resistant to crushing (Alengaram et al., 2013).

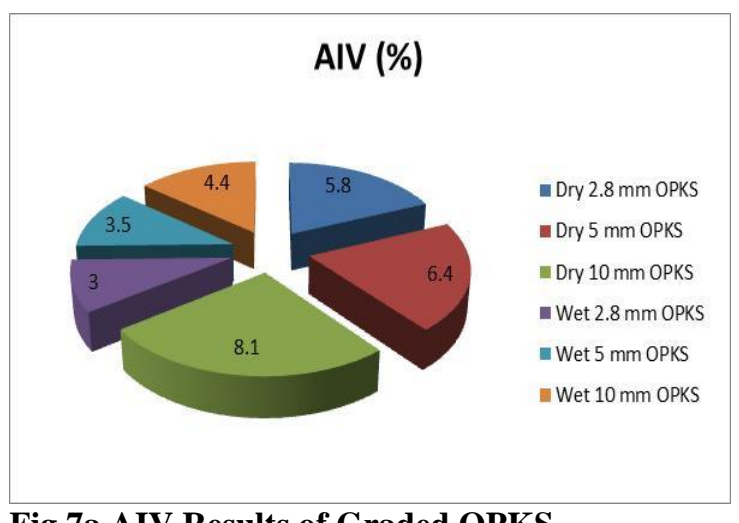

Fig.7a AIV Results of Graded OPKS 
Table 2 Summary of BS Heavy Compaction Results

\begin{tabular}{|c|c|c|c|c|}
\hline \multicolumn{2}{|l|}{ Sample } & \multicolumn{2}{|c|}{$\begin{array}{l}\text { Compaction } \\
\text { Characteristics }\end{array}$} & \multirow[b]{2}{*}{$\begin{array}{l}\text { Air Voids } \\
\text { Ratio }(\%)\end{array}$} \\
\hline OPKS & Soil (\%) & OMC (\%) & $\begin{array}{l}\text { MDD } \\
\left(\mathrm{g} / \mathrm{cm}^{3}\right)\end{array}$ & \\
\hline $0 \%$ & 100 & 15 & 1.81 & 6.5 \\
\hline $10 \%$ of $2.8 \mathrm{~mm}$ & 90 & 17.6 & 1.69 & 4.5 \\
\hline $20 \%$ of $2.8 \mathrm{~mm}$ & 80 & 18.5 & 1.61 & 4.5 \\
\hline $30 \%$ of $2.8 \mathrm{~mm}$ & 70 & 19.5 & 1.49 & 7.5 \\
\hline $10 \%$ of $5 \mathrm{~mm}$ & 90 & 16.1 & 1.72 & 5.5 \\
\hline $20 \%$ of $5 \mathrm{~mm}$ & 80 & 17.1 & 1.65 & 6 \\
\hline $30 \%$ of $5 \mathrm{~mm}$ & 70 & 18.2 & 1.54 & 8 \\
\hline $10 \%$ of $10 \mathrm{~mm}$ & 90 & 16.5 & 1.73 & 4 \\
\hline $20 \%$ of $10 \mathrm{~mm}$ & 80 & 16.8 & 1.7 & 3 \\
\hline $30 \%$ of $10 \mathrm{~mm}$ & 70 & 17.8 & 1.57 & 7 \\
\hline
\end{tabular}

The average water absorption of the $2.8 \mathrm{~mm}$ graded OPKS is $14.72 \%$, that of the $5 \mathrm{~mm}$ graded OPKS is $13.63 \%$ and that of the $10 \mathrm{~mm}$ graded OPKS is $11.61 \%$. The $2.8 \mathrm{~mm}$ graded OPKS absorbed the most water after the 24 hour period of soaking whereas the $10 \mathrm{~mm}$ graded OPKS recorded the least water absorption. The $2.8 \mathrm{~mm}$ OPKS absorbed the most water because it has the largest effective surface area compared to the $5 \mathrm{~mm}$ and $10 \mathrm{~mm}$ graded OPKS (Alengaram et al., 2010b).

\subsection{California Bearing Ratio (CBR) Behaviour}

CBR values of the composites of the natural soil and graded OPKS for both un-soaked and soaked conditions are summarised in Fig. 7b.

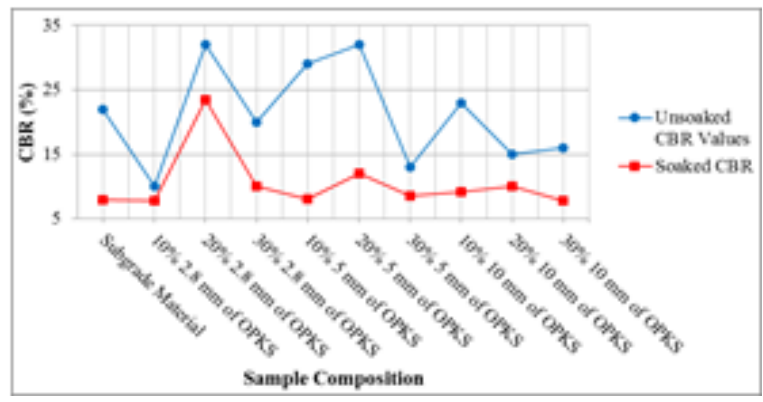

Fig. 7b Soaked and Un-soaked CBR Behaviour

In the un-soaked condition, the natural soil has CBR value of $22 \%$. However, after the samples were soaked for 96 hours, the CBR values reduced as a result of the destruction of the capillary forces. The higher CBR value in the un-soaked condition is because of the capillary forces created at the OMC and MDD state. Furthermore, the un-soaked sample provides a higher resisting friction to the penetration of the plunger (Sridharan, 2012).

The natural soil has a soaked CBR of $7.9 \%$ therefore classifying the sub-grade material into a fair grade (Bowles, 1992). This implies that the natural soil requires capping or it is essential to increase the thickness of the subbase.

Composites containing $80 \%$ natural soil and $20 \%$ of $2.8 \mathrm{~mm}$ graded OPKS and $80 \%$ natural soil plus $20 \%$ of $5 \mathrm{~mm}$ graded OPKS yielded the maximum un-soaked CBR value of $32 \%$. The composite of 80 $\%$ natural soil and $20 \% 2.8 \mathrm{~mm}$ graded OPKS exhibited the maximum soaked CBR value of 23.5 $\%$ which represents a CBR gain of $197.47 \%$ compared to that of the natural soil.

Addition of $20 \% 2.8 \mathrm{~mm}$ graded OPKS to the natural soil increased the CBR value from fair to good sub-grade based on Bowles (1992) quality assessment. A good quality sub-grade does not require capping or an increase in the thickness of the subbase (Anon, 2015). Composites with $10 \%$ of 2.8 mm graded OPKS and $30 \%$ of $10 \mathrm{~mm}$ graded OPKS showed a $1.27 \%$ reduction in the soaked CBR value of the natural soil. The remaining composite materials had higher soaked CBR values in comparison to the natural soil Table $3 \mathrm{a}$.

\subsection{Water Absorption Behaviour of Natural Soil and Composite Materials}

Table $3 \mathrm{~b}$ presents the water absorption results of soaked CBR samples. After soaking the CBR samples, the natural soil sample absorbed the most water while the composites materials absorbed lesser water. Samples compacted by the application of 10 blows showed that the natural soil has the highest amount of water absorption of $7.32 \%$ while the composite materials absorbed lesser amounts of water. The composite made of $10 \% 2.8 \mathrm{~mm}$ graded OPKS absorbed $3.21 \%$ of water which is the least amount of water absorbed by all samples compacted by the application of 10 blows.

Samples compacted by the application of 25 blows portrayed that the natural soil has the highest amount of water absorption of $6.09 \%$ while the composite materials absorbed lesser amounts of water. The composite made of $10 \% 10 \mathrm{~mm}$ graded OPKS absorbed $1.31 \%$ of water which is the least amount of water absorbed by all samples compacted by the application of 25 blows. 
Table 3a Summary Test Results of Natural Soil and Composite Materials

\begin{tabular}{|c|c|c|c|c|c|c|c|c|c|c|c|c|}
\hline \begin{tabular}{|l|} 
Composite \\
Material \\
Mechanical \\
Properties
\end{tabular} & $\begin{array}{l}100 \% \text { Soi } \\
\text { Soil) }\end{array}$ & $\% \mathrm{OP}$ & (Natural & $\begin{array}{ll}90 & \% \\
\text { OPKS }\end{array}$ & +10 & $2.8 \mathrm{~mm}$ & \begin{tabular}{|l}
$80 \%$ \\
OPKS
\end{tabular} & +20 & $2.8 \mathrm{~mm}$ & $\begin{array}{l}70 \% \\
\text { OPKS }\end{array}$ & $+\mathbf{3 0}$ & $2.8 \mathrm{~mm}$ \\
\hline$\overline{\mathrm{OMC}}(\%)$ & & 15 & & & 17.6 & & & 18.5 & & & 19.5 & \\
\hline $\operatorname{MDD}\left(\mathrm{g} / \mathrm{cm}^{3}\right)$ & & .805 & & & 1.69 & & & 1.61 & & & 1.49 & \\
\hline $\begin{array}{l}\text { Air Voids } \\
\text { Ratio (\%) }\end{array}$ & & 6.5 & & & 4.5 & & & 4.5 & & & 7.5 & \\
\hline $\begin{array}{l}\text { Compactive } \\
\text { Effort (Blows) }\end{array}$ & 10 & 25 & 56 & 10 & 25 & 56 & 10 & 25 & 56 & 10 & 25 & 56 \\
\hline \begin{tabular}{ll|}
$\begin{array}{l}\text { Soaked } \\
(\%)\end{array}$ & CBR \\
\end{tabular} & 2.9 & 7.9 & 8.6 & 5.3 & 10.5 & 11.7 & 3.1 & 22.5 & 26 & 18.3 & 20.1 & 15.7 \\
\hline $\begin{array}{l}\text { Soaked CBR } \\
\text { Moisture } \\
\text { Content }(\%)\end{array}$ & 15.3 & 15.2 & 15.2 & 17.5 & 17.7 & 17.8 & 18.1 & 18.5 & 18.3 & 19.4 & 20.1 & 19.6 \\
\hline $\begin{array}{l}\text { Un-soaked } \\
\text { CBR }(\%)\end{array}$ & 17.9 & 21 & 23.1 & 7.7 & 12.7 & 14.6 & 24.9 & 31.2 & 35.6 & 5.7 & 15.5 & 19 \\
\hline $\begin{array}{l}\text { Un-soaked } \\
\text { CBR Moisture } \\
\text { Content }(\%)\end{array}$ & 15.1 & 15.3 & 15.2 & 17.5 & 17.7 & 17.8 & 18.1 & 18.5 & 18.3 & 19.4 & 20.1 & 19.6 \\
\hline $\begin{array}{l}\text { Swell After 96 } \\
\text { hours }(\%)\end{array}$ & 1.2 & 1.6 & 1.6 & 0.4 & 0.9 & 0.4 & 0.9 & 0.9 & 0.9 & 0.9 & 0.4 & 1.3 \\
\hline $\begin{array}{l}\text { Water } \\
\text { Absorbed (\%) }\end{array}$ & 7.32 & 6.09 & 4.79 & 3.21 & 1.41 & 2.35 & 6.64 & 3.57 & 2.1 & 6.81 & 2.74 & 1.71 \\
\hline
\end{tabular}

Table 3b Water Absorption Results of Soaked CBR Samples

\begin{tabular}{|l|c|c|c|c|}
\hline \multicolumn{2}{|c|}{ Sample } & \multicolumn{3}{c|}{ Water Absorption (\%) } \\
\hline \multicolumn{1}{|c|}{ OPKS (\%) } & Soil (\%) & 10 Blows & 25 Blows & 56 Blows \\
\hline $0 \%$ & 100 & 7.32 & 6.09 & 4.79 \\
\hline $10 \%$ of $2.8 \mathrm{~mm}$ & 90 & 3.21 & 1.41 & 2.35 \\
\hline $20 \%$ of $2.8 \mathrm{~mm}$ & 80 & 6.64 & 3.57 & 2.10 \\
\hline $30 \%$ of $2.8 \mathrm{~mm}$ & 70 & 6.81 & 2.74 & 1.71 \\
\hline $10 \%$ of $5 \mathrm{~mm}$ & 90 & 6.62 & 1.49 & 1.37 \\
\hline $20 \%$ of $5 \mathrm{~mm}$ & 80 & 3.26 & 2.01 & 1.94 \\
\hline $30 \%$ of $5 \mathrm{~mm}$ & 70 & 6.74 & 2.65 & 2.03 \\
\hline $10 \%$ of $10 \mathrm{~mm}$ & 90 & 3.27 & 1.31 & 1.18 \\
\hline $20 \%$ of $10 \mathrm{~mm}$ & 80 & 2.57 & 1.64 & 1.26 \\
\hline $30 \%$ of $10 \mathrm{~mm}$ & 70 & 3.76 & 2.44 & 2.51 \\
\hline
\end{tabular}

Samples compacted by the application of 56 blows showed that the natural soil has the highest amount of water absorption of $4.76 \%$ while the composite materials absorbed lesser amounts of water. The composite made of $10 \% 10 \mathrm{~mm}$ graded OPKS absorbed $1.18 \%$ of water which is the least amount of water absorbed by all samples compacted by the application of 56 blows.

\subsection{Effects of Graded OPKS on CBR Swell of Soaked Composites Samples}

Fig. 8 show the CBR swell of the natural soil and the composite materials. Ghana Highway Authority (GHA) standards and specification for roads and bridges stipulates the allowable CBR swell should not exceed $1.5 \%$ for selected fills (Anon. 2001)

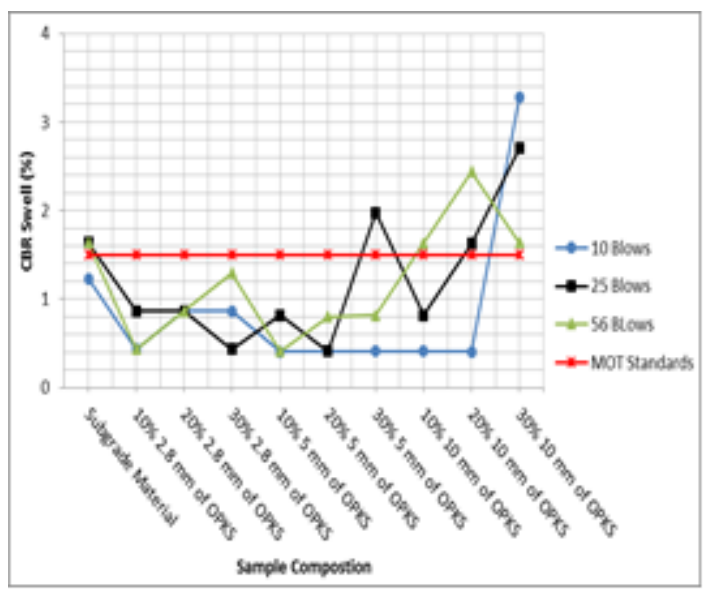

Fig. 8 CBR Swell of Natural Soil and Composite Materials

The composites made of $2.8 \mathrm{~mm}$ graded OPKS had CBR swells within the allowable CBR swell irrespective of number of blows applied. The composites made of $5 \mathrm{~mm}$ graded OPKS had CBR swell within the CBR swell standard with the exception of the composite made of $30 \% 5 \mathrm{~mm}$ graded OPKS and compacted by the application of 25 blows.

The composites made of $10 \mathrm{~mm}$ graded OPKS had three of their CBR swells namely composites made of $10 \%$ of $10 \mathrm{~mm}$ graded OPKS compacted by the application of 10 and 25 blows, and composite material made of $20 \% 10 \mathrm{~mm}$ graded OPKS compacted by the application of 10 blows were within the allowable CBR swell standard; not exceeding $1.5 \%$. The remaining CBR swells for 10 
mm graded OPKS composite materials exceeded the CBR swell standard. Generally, the graded OPKS was able to control CBR swell in comparison to the natural soil.

\subsection{Discussion}

The water absorption behaviour suggests that the presence of graded OPKS in the composite materials limited the amount of water intake into the soil. The highest water absorption of $7.32 \%$ was absorbed by natural soil CBR sample compacted by the application of 10 blows whereas the least water absorption of $1.18 \%$ was absorbed by the composite made of $10 \%$ of $10 \mathrm{~mm}$ graded OPKS that was compacted by the application of 56 blows.

Increasing the proportions of $10 \mathrm{~mm}$ graded OPKS in the composite material results in a reduction of the MDD as compared to that of the natural soil. With this increase, the OMC values increased as compared to that of the natural soil. It is observed from Table $3 \mathrm{a}$, that the composite material with 30 $\%$ of $2.8 \mathrm{~mm}$ graded OPKS has the lowest MDD of $1.49 \mathrm{~g} / \mathrm{cm}^{3}$ and the highest OMC of $19.5 \%$.

The soaked CBR samples made from composites of soil and graded OPKS absorbed less water than that of the sub-grade material. This suggests that the graded OPKS is able to control the amount of water absorbed by the composite material. The $10 \mathrm{~mm}$ graded OPKS has the least resistance to crushing. In general, the wet graded OPKS are more resistant to crushing than the dry ones. This behaviour can be explained by the fact that the OPKS are absorbent, porous, elongated and flaky and as such the dry and/or bigger sized OPKS stand a higher chance of breaking and crushing when subjected to sudden impact and shock loads.

\section{Conclusions and Recommendations}

\subsection{Conclusions}

The potential of graded OPKS to improve the geotechnical properties of a fair quality sub-grade material was evaluated in this thesis. From the discussion, the following conclusions have been drawn:

(i) The soaked CBR value of $7.9 \%$ for the soil indicates that the quality of the sub-grade is fair, suggesting that the sub-grade requires capping, an increased subbase thickness or some ground improvement to enhance its load bearing capacity. (ii) The soaked CBR values are lower than the un-soaked CBR values. This behaviour suggests that there is no bonding between the sub-grade material and the graded OPKS.

(iii) The addition of graded OPKS to the soil increased the OMC and decreased MDD. The decrease in MDD implies that, when more of this composite material is supposedly used for road construction it will be able to increase the total pavement structure thickness thereby reducing the stresses induced in the sub-grade with depth. This is so because there is a larger pavement thickness to bear the traffic load and also the dead load imposed by road foundation will be reduced.

(iv) The composite material made of $80 \%$ of soil and $20 \%$ of $2.8 \mathrm{~mm}$ graded OPKS yielded the maximum soaked and un-soaked CBR values of $32 \%$ and $23.5 \%$ respectively. An increased CBR value implies the subgrade can bear higher traffic loads. It also means the total pavement structure thickness can be reduced thus reducing the dead load imposed by the pavement structure on the road foundation or sub-grade material.

\subsection{Recommendations}

The aim and scope of this research was limited to laboratory works. For future related works the following considerations are recommended.

(i) Long term effects of graded OPKS as a soil improvement material in the field should be investigated.

(ii) The water absorption control of the graded OPKS in the composite material should be further investigated using expansive soils. This further study will confirm if graded OPKS can control groundwater rise in expansive soils.

\section{References}

Adejumo, T. W., Alhassan, M. and Boiko, I. L. (2012), "Physico-mechanical Properties of Some Major Weak Soils in Nigeria", The Electronic Journal of Geotechnical Engineering, Vol. 17/Q, pp. 2435 - 2441.

Alengaram, U. J., Jumaat, M. Z. and Mahmud, H. (2008), "Ductility Behaviour of Reinforced Palm Kernel Shell Concrete Beams", European Journal of Scientific Research, Vol.23, No.3, pp. $406-420$. 
Alengaram, U. J., Jumaat, M. Z. and Mahmud, H. (2010a), "Structural Behaviour of Reinforced Palm Kernel Shell Foamed Concrete Beams Challenges", Opportunities and Solutions in Structural Engineering and Construction Ghafoori (ed), Taylor \& Francis Group, London, $6 \mathrm{pp}$.

Alengaram, U, J., Mahmud, H., Jumaat, M. H. and Shirazi, S. M. (2010b), "Effect of Aggregate Size and Proportion on Strength Properties of Palm Kernel Shell Concrete", International Journal of the Physical Sciences, Vol. 5 (1 2), pp. 1848 1856.

Alengaram, U. J., Muhit, B. A. Al. and bin Jumaat, M. Z. (2013), "Utilization of Oil Palm Kernel Shell as Lightweight Aggregate in Concrete - A review", Construction and Building Materials, Elsevier Publishing, Vol. 32, pp. 161 -172.

Ameratunga, J. (2013), "Ground Improvement in Road Projects - Australian Experience", Coffey Geotechnics/National Building Research Organisation, Unpublished Paper, 8 pp.

Anon (2001), 'Ghana Highway Authority road maintenance work procedure' Vol. 3, pp.1-14

Anon. (2015), "Pavement Design - Foundation Design', http://www.archive.officialdocuments.co.uk/document/ha/dmrb/index.htm. Accessed: April 29, 2015.

Bell, F. G. and Culshaw M. G. (2001). Problem Soils: A Review of British Perspective, Thomas Telford Publishing, $1^{\text {st }}$ Edition, London, 36 pp.

Bowles, J. E. (1992), Engineering Properties of Soils and Their Measurement, McGraw-Hill, $4^{\text {th }}$ Edition, $481 \mathrm{pp}$.

Briscolland, R. and Chown, R. (2001), "Problem Soils: A Review from a British Perspective", Proceeding of Problematic Soils Conference, Nottingham, pp. 53 - 66.

Indraratna, B., Rujikiatkamjorn, C., Vinod, J. S. and Nimbalkar, S. (2011). "Physical and Chemical Ground Improvement for Sustainable Transportation Infrastructure Under Cyclic Loads", Geotechnical Engineering for Disaster Mitigation and Rehabilitation and Highway Engineering 2011: Proceedings of the 3rd and 5th International Conference Semarang, Indonesia, pp. 140 - 156.

Lartey, R. B., Acquah F. and Nketia, K. S. (1999), "Developing National Capability for Manufacture of Activated Carbon from Agricultural Wastes CSIR" The Ghana Engineer, pp.1-5.

Madjadoumbaye, J., Kamdjo, G., Mbessa, M., Defo, F. E. H. and Tamo, T. T. (2013), "Possibilities for Improving the Bearing Capacity of Laterite with a Vegetable Shell: the Shell of Palm Kernels", The Electronic Journal of Geotechnical Engineering (EJGE), Vol. 18, Bund. J, pp. $1917-1928$

Mathew, T. V. and Rao, K. V. K. (2007), "Introduction to Pavement Design", Unpublished Lecture Notes, Nptel, 7 pp.

Raju, V. R. and Valluri, S. (2008), "Practical Applications of Ground Improvement", Symposium on Engineering of Ground \& Environmental Geotechniques, S EG2, Hyderabad, 12 pp.

Singh, S. P., Tripathy, D. P., and Ranjith, P. G., (2008), "Performance Evaluation of Cement Stabilized Sly Ash-GBFS Mixes as a Highway Construction Material", Science Direct - Waste Management, ELSERVIER, Vol. 28, Issue 8, pp. $1331-1337$

Sridharan, A. (2012), "Coal Ashes in Geotechnical Engineering Practice; Beneficial Aspects", Proceedings of National Workshop on Emerging Trends in Geotechnical Engineering (ETGE), Edited by Krishna, A. M., Indian Institute of Technology Guwahati, pp.11 - 25.

Yap, S. P., Alengaram, U. J., Jumaat M. Z. and Foong K. Y. (2013), "Waste Materials in Malaysia for Development of Sustainable Concrete:A Review", Electronic Journal of Structural Engineering, Vol. 13(1), pp. 60 - 64.

Zhu, Z. D. and Liu, S. Y. (2008). "Utilization of a New Soil Stabilizer for Silt Sub-grade". Engineering Geology, 97, pp. 192 - 198.

\section{Authors}

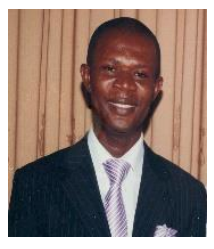

Michael Affam is currently an Associate Professor with the Department of Geological Engineering, University of Mines and Technology (UMaT), Tarkwa, Ghana. He holds $\mathrm{PhD}$ degree in Geological Engineering (Geotechnical option) from UMaT/ Queens University, Canada, MSc and BSc degrees from Kwame Nkrumah University of Science and Technology, Kumasi. Ghana. His specialty is in advances in geomechanics, foundation design and exploration techniques

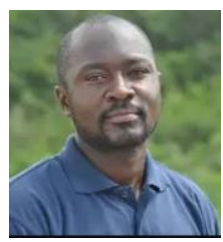

Rodney Ewusi Wilson is currently a Geological Consultant. He holds MSc Degree in Geological Engineering from University of Mines and Technology (UMaT), Tarkwa and BSc Degree in Geological Engineering from Kwame Nkrumah University of Mines and Technology (KNUST), Kumasi. His research interest is soil improvement techniques and stabilization.

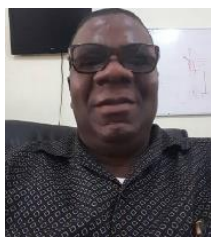

Mapping.
Daniel Asenso-Gyambibi is a Snr. Research Scientist with the CSIR-Building and Road Research Institute.He holds both MPhil and BSc degrees in Geomatic Engineering from University of Science and Technology, Kumasi. His areas of interests are Geographic Information System Land Administration, Survey and 